\title{
A causal model of public health administration, need for mental health care, and mental health status associated with mental health service utilization among Asian immigrant employees after ASEAN community's policy
}

Chonticha Kaewanuchit ( $\sim$ sim356@yahoo.com )

Phranakhon Si Ayutthaya Rajabhat University https://orcid.org/0000-0002-4291-6215

\section{Yothin Sawangdee}

Institute of Population and Social Research, Mahidol University, Nakhon Pathum province

\section{Research article}

Keywords: Public health administration, Need for mental health care, Mental health status, Asian immigrant employees, Mental health service utilization

Posted Date: October 16th, 2019

DOI: https://doi.org/10.21203/rs.2.16130/v1

License: (c) (1) This work is licensed under a Creative Commons Attribution 4.0 International License. Read Full License 


\section{Abstract}

Background One important outcome national and international migration is the development of economies and societies worldwide. A rapid change amongst Asian immigrant employees who were working and settling down in Thailand, especially, Burmese, Lao, and Cambodian was that it lead to poor physical health and mental health. It lead into an incremental need for a system of public health administration because of the difficulties in accessing both the health service and beneficial health information after ASEAN community's policy. The aim of this research was to analyze a causal model of public health administration, the need for mental health care, and mental health status associated with mental health service utilization among Asian immigrant employees after ASEAN community's policy.

Methods This study was conducted using a cross-sectional survey with 400 Asian immigrant employees. They were Burmese (200 cases), Lao (100 cases), and Cambodian (100 cases) in 2017. Measures included general characteristics, public health administration, the need for mental health care, and mental health status associated with mental health service utilization. A causal model for mental health service utilization among Asian immigrant employees were verified using path analysis.

Result s Public health administration, the need for mental health care, and mental health status in each group all have a direct effect on mental health service utilization. Public health administration among Asian immigrants employees following the ASEAN community policy had the most direct effect on mental health service utilization with a standardized regression weight of 0.758 ( $p$-value < 0.01 ). The ASEAN community policy; a mediator of this research, also had a direct effect on mental health service utilization.

Conclusion This research demonstrates that Public health administration was an important factor related to mental health service utilization among Asian immigrants employees following the ASEAN community policy. It also recommends using qualitative methods for further research among Asian immigrant employees who are from developing countries.

Key words: Public health administration; Need for mental health care; Mental health status; Asian immigrant employees; Mental health service utilization

Trial Registration Number: The Thai Clinical Trials Registry code, Thailand was TCTR20170713001.

\section{Background}

One important outcome national and international migration is the development of economies and societies worldwide [1].In the past, migration was slow process among Thai immigrant employees. When Thai society formed the AEC (Asian Economic Community) society two years ago, a researcher in Thailand studied the path analysis of mental health among Thai immigrant employees who worked in Pranakron Si Ayutthaya Province, Thailand. It found that job conditions and the distance travelled between their home and workplace had a direct effect on mental health [1]. This research implied that job conditions were an important factor related to mental health [1]. This point reflected that not only national migration but also international migration is sensitive, especially, among Asian immigrant employees (e.g. Burmese, Lao, and Cambodian) 
who need to work in Thailand. Data from the Bureau of registration administration, Ministry of the Interior, Thailand reported that the total population of Thailand on February $12^{\text {th }}, 2016$ was $65,931,550$ people. They were divided into Thai nationality $(65,096905$ people) and international nationalities ( 834,645 people) on December $31^{\text {th }}, 2015$ [2]. The international population was $1.26 \%$ of the population in Thailand. However, the international population increased in 2015 and 2016. It is different from 2014 where it was (only $0.5 \%$ of the overall population of Thailand) [3].Besides, data from the International Organization for Migration (IOM) in 2014 reported that migrant population of Thailand (e.g. Burmese, Lao, and Cambodian) who worked and lived in Thailand, comprised of 2,766, 968 people of which only 1,082892 people (39.13\%) had work permits [4]. The Thai policy for international migration allowed Burmese, Lao, and Cambodians to work in low skilled jobs and legally register based on a Memorandum of Understanding (MOU) signed in $2003[5,6]$. Asian immigrant employees mainly worked in Bangkok, and the Bangkok Metropolitan Region (e.g. Nonthaburi, Pathomthani, Nakhon Pathum, Samutsakorn, and Samutprakarn Provinces). Generally, they worked in the service sector (18.1\%), agricultural sector (16.9\%), construction (16.8\%), fisheries (10.4\%), and domestic service (9.9\%) [7].

A rapid change amongst Asian immigrant employees who were working and settling down in Thailand, especially, Burmese, Lao, and Cambodian was that it lead to poor physical health (e.g. STD, dengue fever, malaria, diarrhea etc.) [8-10], poor mental health (e.g. occupational stress, stress from unemployment, no health insurance and work permits, depression from homesickness, anxiety about the language, hard work with, not enough rest, and feelings of exploitation and exclusion etc.) [11].

It lead into an incremental need for a system of public health administration because of the difficulties in accessing both the health service and beneficial health information [11].The Commonwealth Association for Public Administration and Management (CAPAM) concluded that a new structure of public health administration related was needed, which was both demand and technology driven. It focused on the macrostructural factor of public health administration among immigrant employees such as; the mental health care system, mental health service management, and the twin contexts of emigration and reception [12]. In the USA, the mental health care system called for a new Obama care system which managed only immigrant employees under The Affordable Care Act with co-payments for health insurance [12]. Meanwhile, the Ministry of Public Health in Thailand forced Burmese, Lao, and Cambodians; who are Asian immigrant employees, to buy some health insurance [2]. Mental health service management is related to convenience within the context of emigration as well as in Cuban immigrant employees[13] who used the mental health service in the community health system in Cuba before they were transferred to the mental health service in Florida which has a mental health transfer system [13]. Rather, African, Asian, and Latin America immigrant employees who did not have a universal health care system in their country exhibited a negative trend for this service [14]. This is in contrast to the context of the reception associated with public health administration at government, social, and community level [13]. For example, government policy is to take care of and cure health issues among new immigrant employees and to tackle social exclusion and discrimination; in addition, to work within employer countries including passive acceptance active encouragement, and adapt attitudes towards race, class, religion, and language among immigrant employees [13]. 
The public health system of Thailand providing care for the mental health of Asian immigrant employees is based on the mental health care system developed under the ASEAN community's policy. It reports about mental health care among Burmese to use as guidelines to develop mental health work practices and to report on the mental health of refugees $[15,16]$.

The ASEAN (Association of Southeast Asian Nations)community policy issue, and the Sustainable Development Goals (SDGs) contain a wellbeing health target set by WHO and the UN [17]. The ASEAN community policy is related to the ASEAN political and security community (APSC), and the ASEAN economic community (AEC), ASEAN social and cultural community (ASCC) [18]. Health issues fall under ASCC which focuses on providing a social safety net and protection from the negative impacts of integration and globalization including access to healthcare and the promotion of healthy lifestyles. Issues effecting Asian immigrant employee fall under The ASEAN occupational safety and health network in each country [18]. With the main focus on safety in work rather than mental health.

The issue of the need for mental health care and mental health service utilization among Asian immigrant employees from previous studies found that they studied only the need general health care, from self-related health and physician-rated health indicators as independent predictors of mortality in elderly men [19]. They also focused on the predictive value of self-assessed general, physical, and mental health on functional decline and mortality in older adults [20], based on self- and physician-rated general health in relation to symptoms and diseases among women [21]. Some research projects studied the discordance between physicians and patient self-related health and all-cause mortalities[22] similar to the health status and health care utilization patterns between foreigners and the national population in Spain [5].

Therefore, it is important and necessary to analyze a causal model (e.g. direct, indirect, and total effect) of public health administration, the need for mental health care, and mental health status associated with mental health service utilization among Asian immigrant employees under the ASEAN community's policy.

The operational definitions from this research consist of (i) public health administration means the macrostructural factors in public health administration which are associated with the mental health care system, mental health service management, the context of emigration and reception, (ii) ASEAN community policy means policy about access to healthcare and the promotion of healthy lifestyles, and mental health care among Burmese, Lao, and Cambodians, (iii) need for mental health care means immigrant-specific mental health needs/ conditions among Burmese, Lao, and Cambodians including issues of health insurance under the government, employment practices leading to poor mental health, discrimination, language differences, mental health services in their country of origin, health costs, and information, (iv) mental health status means unhappiness, anxiety, social impairment, and hypochondriasis (using General Health Questionnaire in Thai version), (v) mental health service utilization means factsheets cell phones, websites, web boards, and email being used to contact physician within the previous year.

\section{Methods}

\section{Sample and recruitment}


A cross-sectional study was conducted among Asian immigrant employees who are between the ages 20 and 59 years old. The sample design included Burmese (200 cases), Lao (100 cases), and Cambodian (100 cases). They still worked in Bangkok, which is the capital city of Thailand, and in Nakhon Pathum, Phranakhon Si Ayutthaya, and Nonthaburi provinces. These provinces are important and major economic areas. The research recruiters undertook nonprobability sampling which used a quota sampling method to select Asian immigrant employees. They screened participants for the following inclusion criteria: selfidentified as Asian immigrant employees who spoke the Thai language. In contrast, Asian immigrant employees who worked and lived in other provinces were excluded. The sample size was calculated using the M-plus guideline. It considered no less than 10-20 times the number of parameters for the path model. It has five observed variables used for identification. They were public health administration, need for mental health service, mental health status, ASEAN community's policy, and mental health service. Thus, the sample size was 300 participants. In this case, we used a total of 400 participants as it is a large enough number of people to decrease proportional errors.

\section{Instruments}

Measures formed from four parts (42 questions) were considered: (i) general characteristic (7 questions), (ii) public health administration, the need for mental health care, and mental health status associated with mental health service utilization (18 questions), (iii) Thai General Health Questionnaire (Thai-GHQ) (12 questions), and (iv) mental health service utilization (5 questions).

First, individual characteristics included race, sex, education, marital status, work employment, and job characteristic. Second, public health administration measures comprising of six items from the applied questionnaire were assessed, which were rooted on public health perspectives. The selected items asked the participants about the mental health system and services, the public mental health administration of Thailand, social exclusion and exploitation by the mental health administration. The response options ranged from "none" (1) to "most" (4). Cronbach's alpha coefficient of public health administration among Asian immigrant employees was 0.80 . Moreover, the need for mental health care measures were assessed with applied questions ( 7 items). The selected items asked about their health insurance card from the Thai government, work employment effects on their mental health, and exclusion and exploitation of the Asian immigrant employees by the Thai employers. Other considerations were different language affects the need for mental health care, the lack of mental health services from countries of origin, lack of information about mental health care, and the high costs of mental health care. Cronbach's alpha coefficient in the need for mental health care was 0.79 . All items in the scale used the 4-point scale format. Third, the mental health status measure was assessed [23] by using items modified from the General Health Questionnaire (GHQ) [24]. The 12-items Thai version of the GHQ measure has been used as the screening instrument for common mental disorders and as a more general measure of psychiatric well-being in Thai community settings. It was developed from the 12 items GHQ [24].The version of the Thai GHQ-12 had good reliability and validity, with the range of Cronbach's alpha coefficients at 0.95 , and the range of sensitivity and specificity at $85.3 \%$ and $89.7 \%$ respectively [24]. For example, the Thai GHQ-12 questions consisted of (1) ability to concentrate, (2) loss of sleep due to worry, (3) playing a useful part, (4) being capable of making decisions, (5) being 
constantly under strain, (6) inability to overcome difficulties, (7) ability to enjoy day-to-day activities, (8) ability to face problems, (9) feeling unhappy and depressed, (10) losing confidence, (11) thinking of self as worthless, and (12) feeling reasonable happy. It relates to somatic symptoms, anxiety and insomnia, social dysfunction, and severe depression. Twelve of the items in the scale used a binary (0-0-1-1) score to obtain the psychiatric prevalence rate and the Likert's scale [24]for performing the data analysis used in this research. The total scores are more than two indicating an abnormal mental health status. The total ThaiGHQ was calculated by summing the items ( = 0.95) among Asian immigrant employees following ASEAN community policy. Verification of the data accuracy was passed in terms of content validity by five professors who were an expert in public health and the construct validity was validated by the Carver method [25]. The Index of Item-Objective Congruence (IOC) of the content validity was 0.85 and the construct validity was 0.82. Reliability was examined using Cronbach's alpha coefficient[26] in the SPSS program version 20. This questionnaire's reliability was 0.90 . Finally, part four of the mental health service utilization with five items was from an applied questionnaire. For example, the use of the government mental health service, telephone use when consulting about mental health problem with the government service, using emails to ask about government mental health services, using websites or web boards to consult about mental health problems with government mental health services and to obtain physician appointments to check, consult about and treat mental health problem within the past year. The response options ranged from "none" (1) to "most" (4). The Cronbach's alpha coefficient of mental health service utilization among Asian immigrant employees was 0.89 .

\section{Data collection}

Before the data collection was undertaken, this research was accepted by the Human Ethics Committees from Mahidol University, Nakhon Pathum province, Thailand; the code was COA. No. 2017/06-127 while the Thai Clinical Trials Registry code was TCTR20170713001. Data were collected by the researchers and assistant researchers. Self-administered surveys were conducted in public places (e.g. parks, roadsides, factories, gas stations, etc.) and in the participants' homes. The principal investigator gave a detailed description of the entire questionnaire to the assistance researchers. If the participants had difficulties understanding the questions, the researchers provided further explanations. All participants took approximately 30 minutes to complete the questionnaire. After that, all of the completed questionnaires from the participants were put in a sealed container (e.g. box and envelope).

\section{Data analysis}

We adjusted all the statistical analyses for the quota sampling design of this research, then summarized the sample by using minimum, maximum, means, and standard deviation for the continuous data, and percentages for the categorical data in this research. Finally, we analyzed a causal model by using path analysis for the continuous variables. We presented maximum likelihood estimates, a path analysis of variance, analysis of the $\mathrm{R}$ square, and measurement of the goodness of fit of the path analysis using $M$ plus version 5.2 and we considered p-values of less than 0.01 , and 0.05 statistically significant. The rule of the path model was fitted for a population of over 250 people and it was observed that variables of less than 
12 were acceptable, with a chi-square not equal to 0 as well as degree of freedom, and with a p-value of more than 0.05, a Comparative Fit Index (CFI) / TLI (Tucker-Lewis Index) of more than 0.95 , and finally a Root Mean Square Error of Approximation (RMSEA) of less than 0.07 , with a Standardized Root-MeanSquare Residual (SRMR) of less than 0.05 [27].

\section{Results}

Participant general characteristics are presented (Table 1,2). Subsequently, the model fit of the causal model was deemed acceptable (Table 3). In this causal model among Asian immigrant employees following ASEAN community's policy, the addition of various factors increased the explanation of the variance in mental health service utilization by $66.6 \%$ ( $p$-value $<0.01$ ) (Table 3 ). This model displayed a mediating effect on the causal factors in the relationship between the public health administrations, the need for mental health care, and mental health status associated with mental health service utilization (Table 4).

\section{Discussion}

This highlighted empirical research is the first outstanding research finding for Thailand because it is related to mental health risks among Asian immigrant employees which have an effect on Thai people, Thai society and The ASEAN Occupational Safety and Health Network [18]. The Thai government should set up a good public health administration, to increase the availability of mental health services and to reduce the poor mental health status[28] linked to the introduction to the WHO Commission on Social Determinants of Health Employment Conditions Network (EMCONET) Study, with a glossary on employment relations [29].

Importantly, public health administration should be linked to the mental health care system, mental health service management, the context of emigration, and the context of reception. Some studies report that mental health service management is related to convenience within the context of emigration as in Cuban immigrant employees[13] who used the mental health service in the community health system in Cuba before they were transferred to the mental health service in Florida who was then transferred into the mental health system [13]. But African, Asian, and Latin America immigrant employees who did not have a universal health care system exhibited negative trends for this service [14]. However, the public health administration of Thailand for the health of Asian immigrant employees prepared the mental health care system following the ASEAN community's policy $[15,16]$. It reported mental health care among the Burmese using guideline to develop mental health work and to report on the mental health of refugees $[15,16]$. Empirical results from this research show that public health administration variables were the most consistently associated factors in mental health service utilization. It indicates that the public health administration has an important causal relationship with mental health service utilization. Mental health status, and the need for mental health care are the second, and third causal relationships associated with mental health service utilization among Asian immigrant employees. That is to say, it can also be observed that both mental health status and the need for mental health care had both direct and indirect effects on the mental health service. Moreover, it can be considered that both directly affect the ASEAN community's policy. This should be studied in the future. 
Other studies such as Latino[30], Cambodian, Iranian, Iraqi people, Vietnamese, African, and Eastern European[31] have also reported on immigrant employees. For example, Latina hotel housekeepers who were immigrant employees and who were exposed to dirt, dust and social exclusion including time limitations when for working in hotels leading to stress [30]. They needed to use the health service but they could not use it because of a lack of accessibility to both physical and mental health care [30]. In addition, economics, discrimination, language differences, employment, lack of mental health services in country of origin, cost, and a lack of information had an effect on their need for mental health care and mental health service utilization [31, 32]. Therefore, research about the associations between public health administration, the need for mental health care, and mental health status associated with mental health service utilization among Asian immigrant employees following the ASEAN community's policy remains limited. This analysis builds upon this research and supports the importance of causal relationships, especially, the causal model for understanding and improving public health administration based on the occupational health of vulnerable Asian immigrant employees. This is among the first attempts to include measures from each variable of the causal model in one analysis.

Moreover, the public health perspective is based on psychosocial occupational health hazards related to public health administration [33]. Generally, the public health system does not pay sufficient attention to psychosocial occupational health hazards (e.g. mental health status and job stress) and public health administration focused on the mental health management among immigrant employees [33].

There were several limitations in the present research. Firstly, the participants of this research were of three races (e.g. Burmese, Lao, and Cambodian). Its limitation was language difference, except, for the Lao who used the Thai language making it easier for them to understand. But the communication difficulties with the Burmese, and Cambodian did not make it easy to answer some questions. They are Asian temporary immigrant employees. Secondly, the main limitation of this research is that it focused only on Asian immigrant employees (e.g. Burmese, Lao, and Cambodian) because of budget limitations. So it also did not study all of the other immigrant employees when it should have included them. The final limitation of this study is that its methodology only uses the causal model, which is quantitative analysis, to create an understanding about what the real causes are. The recommendation is that it should also have used qualitative methods. Good examples of this are in-depth interviews, focus groups, and observation. In addition, it should also use SEM for analysis the next time this area is studied.

The strengths of this study are that the first causal model explained $66.6 \%$ of the variance in mental health service utilization. It implied that the model fit of the causal model was strongly acceptable. There has only been one report of this type of study attempting to analyze the causal relationship between the public health administration, the need for mental health care, and the mental health status associated with mental health service utilization among Asian immigrant employees following ASEAN community policy by using the causal model. It can lead towards some guidelines for the development of mental health policy and public health administration. Even though, this research has a strong sample design, a large enough sample size, a high participation rate, an extensive collection of information, and the use of existing mental health service utilization measures. But, for some future studies, there should expand the factors of the need for mental health care with over time, race, economics, social exclusion and discrimination among Asian immigrant 
employees. In addition, it should also use some qualitative methods i.e. focus group discussion subsequent research among Asian immigrant employees who are from developing countries.

\section{Conclusions}

This original research displays that Public health administration was an important factor related to mental health service utilization among Asian immigrants employees following the ASEAN community policy. An important causal model showed $66.6 \%$ of the variance in mental health service utilization. It also suggests using qualitative methods in the next research among Asian immigrant employees who are from developing countries in worldwide.

\section{Declarations}

1.Ethics approval and consent to participate

This research was accepted by the Human Ethics Committees from Mahidol University, Nakhon Pathum province, Thailand; the code was COA. No. 2017/06-127 while the Thai Clinical Trials Registry code was TCTR20170713001. Informed consent was obtained from all individual participants included in this research.

2.Consent for publication

Not applicable

3.Availability of data and material

The datasets of this study are available from the corresponding author on reasonable request.

4. Competing interests

The authors declare no conflicts of interest.

\section{Funding}

This research was supported by the National Research Council of Thailand (NRCT), Thailand.

\section{Authors' contributions}

CK collected, analyzed and interpreted the data. CK was a major contributor in writing the manuscript. YS suggested to CK in writing this manuscript for publication. All authors read and approved the final manuscript.

\section{Acknowledgements}

Authors would like to thank the National Research Council of Thailand (NRCT), Thailand for research supporting. 


\section{References}

1. Kaewanuchit C, Sawangdee Y. A path analysis of mental health among Thai immigrant employees in Pranakron Si Ayutthaya Province. J Immigr Minor Health. 2016;18(4): 871-7.

2. The Bureau of registration administration, Ministry of the Interior, Thailand. 2017. Available at http://stat.bora.dopa.go.th/stat/y_stat59.htm. Accessed 13 Sep 2017.

3. Ministry of the Interior, Thailand. 2016. Available at http://stat.dopa.go.th/stat/statnew/upstatage_disp.php. (2016). Accessed 11 June 2016.

4. International Organization for Migration. Launch of the Thailand Migration Report 2014. Bangkok: IOM; 2014.

5. Hernandex-Quevedo C, Jimmenez-Rubio D. A comparison of the health status and health care utilization pattern setween foreigners and the national population in Spain: New evidence from the Spainish National Health Survery. Soc. Sci. Med.2009;69:370-8.

6. ILO. Regulating recruitment of migrant workers: An assessment of complaint mechanisms in Thailand. Bangkok: ILO; 2013.

7. Kulkolkarn K. Study on immigrant policy and management in Singapore, Malaysia, Brunei, South Korea, Taiwan, United States, and its relevance to Thailand. Bangkok: The Thailand research fund; 2014.

8. Burea of Policy and Strategy. National Tuberculosis programme, Thailand: situation and activities, Ministry of Public Health. Nonthaburi: Ministry of Public Health; 2013.

9. Hewitt S, Delacollete C, Chavez I. Malaria situation in the Grater Mekong Sub-region. Southeast Asian J Trop Med Public Health. 2013;44 (1):46-7.

10. Jithai N. Migrants and malaria. Southeast Asian J Trop Med Public Health. 2013;44 (1):166-200.

11. Department of Mental Health, Thailand. Mental health issue for resettle refugees. 2016.

Available at http://ethnomed. org/clinical/mental-health/mental-health. Accessed 1 June 2016.

12. Bustamante AV, Fang H, Garza J, Carter-Pokras O, Wallace SP, Rizzo JA, Ortega AN. Variations in healthcare access and utilization among Mexican immigrants: the role of documentation status. J. Immigr. Minor. Health. 2012;14:146-55.

13. Portes A, Rumbaut R. Legacies: The story of the immigrant second generation. Berkely: University of California Press; 2001.

14. Sanz B, Regidor E, Galindo S, Pascual C, Lostao L, Diaz JM, Sanchez E. Patten of health services use by immigrants from different regions of the world residing in Spain. Int J Public Health. 2011;56:567-76. 
15. Kittirattanapaiboon P. Mental Health-Myanmar Refugee Maunal. Nonthaburi: Department of Mental Health; 2013.

16. Department of Mental Health, Thailand. Mental health issue for resettle refugees. 2016. Available at http://ethnomed. org/clinical/mental-health/mental-health. Accessed 1 June 2016.

17. WHO. UN Sustainable Development Summit 2015. 2016. Available at www.who.int/mediacentre/events/meetings/2015/un-sustainable-development-summit. Accessed 1 June 2016.

18. The ASEAN Occupational Safety and Health Network. ASEAN-OSHNET Occupational safety and health management system (OSHMS) initiatives 2011/2012. Bangkok : Ministry of Labor; 2015.

19. Gilay EJ, Vollaard AM, Kromhout D. Self-related health and physician-rated health as independent predictors of mortality in elderly men. Age Ageing. 2012;41:165-71.

20. Lee Y. 2000. The predictive value of self-assessed general, physical, and mental health on functional decline and mortality in older adults. J Epidemiol Community Health. 2002;54:123-9.

21. Mellner C, Lundberg U. Self- and physician-rated general health in relation to symptoms and diseases among women. Psychol Health Med. 2003;8:123-34.

22. DeSalvo KB, Muntaner P. 2011. Discordance between physician and patient self-related health and allcause mortality. Ochsner J. 2011;11:232-40.

23. Nilchaikovit T, Sukying C, Silpakit C. Reliability and validity of the Thai version of the General Health Questionnaire. J Psychiatr Assoc Thailand. 1996;41(1):2-17.

24. Goldberg D, Williams P. A user's guide to the General Health Questionnaire. Windsor, UK: NFER-Nelson; 1988.

25. Carver RP. Two dimensions of tests: psychometric and edumetric. Am Psychol. 1974;29:512-8.

26. Cappelleri JC, Zou KH, Bushmakin AG, Alvir JJ, Alemayehu D, Symonds T. Patient-report outcome measurement, implementation and interpretation. U.S.A. : CRC Press; 2014.

27. Hair JE, Black WC, Babin BJ, Anderson RE. Multivariate data analysis with reading. 7th ed. New Jersey: Prentice Hall, Inc.; 2009.

28. Ministry of Public Health in Thailand. Thailand global and ASEAN health strategies: moving towards integrated ASEAN community and equitable global health 2012 - 2016. Nonthaburi : Ministry of Public Health; 2016.

29. Benach J, Muntaner C, Solar O, Santana V, Quinlan M, \& EMCONET Network. Introduction to the WHO Commission on Social Determinants of Health Employment Conditions Network (EMCONET) Study, with a Glossary on Employment Relations. Int J Health Serv. 2010;40:195-207. 
30. Hsieh Y, Apostolopoulos Y, Sonmez S. Work conditions and health and well-being of Latina hotel housekeepers. J Immigr Minor Health. 2016;18:568-81.

31. Saechao F, Sharrock S, Reicherter D, Livingston JD, Aylward A, Whisnant J, Koopman C, Kohli S. Stressors and barriers to using mental health services among diverse groups of first-generation immigrants to the United States. Community Ment Health J. 2012 Feb;48(1):98-106. doi: 10.1007/s10597-011-9419-4. Epub 2011 Jun 8.

32. Yang PQ, Hwang SH. Explaining immigrant health service utilization: a theoretical framework. SAGE Open. 2016;April-June:1-15.

33. Gatchel RJ, Schultz IZ. Handbook of occupational health and wellness. New York: Spinger Science+Business Media; 2012.

\section{Tables}

Table 1 Percentage of general geographic data among Asian immigrant employees after ASEAN community's policy $(\mathrm{N}=400)$ 


\begin{tabular}{|c|c|c|}
\hline & Data & Percentage \\
\hline Race & $\begin{array}{l}\text { Burmese } \\
\text { Lao } \\
\text { Cambodian }\end{array}$ & $\begin{array}{l}25.0 \\
50.0 \\
25.0\end{array}$ \\
\hline Sex & $\begin{array}{l}\text { Female } \\
\text { Male }\end{array}$ & $\begin{array}{l}45.0 \\
55.0\end{array}$ \\
\hline Education & $\begin{array}{l}\text { Primary school } \\
\text { Secondary school } \\
\text { Bachelor degree } \\
\text { No education }\end{array}$ & $\begin{array}{c}35.0 \\
60.4 \\
3.6 \\
1.0\end{array}$ \\
\hline Marital status & $\begin{array}{l}\text { Single } \\
\text { Window } \\
\text { Marriage }\end{array}$ & $\begin{array}{r}30.0 \\
3.3 \\
66.7\end{array}$ \\
\hline Age (year old) & $\begin{array}{l}20-29 \\
30-39 \\
40-49 \\
50-59\end{array}$ & $\begin{array}{c}43.3 \\
26.7 \\
25 \\
5\end{array}$ \\
\hline Occupational employment & $\begin{array}{l}\text { Permanent employee } \\
\text { Temporary employee } \\
\text { Others }\end{array}$ & $\begin{array}{c}38.7 \\
56.3 \\
5\end{array}$ \\
\hline Job characteristic & $\begin{array}{l}\text { General contractor } \\
\text { Merchant } \\
\text { Refuel service employees } \\
\text { Car cleaner } \\
\text { Waiter/waitress } \\
\text { Cleaner at hotel/ accommodation } \\
\text { Employee in industrial sector } \\
\text { Employee in agricultural sector } \\
\text { Others }\end{array}$ & $\begin{array}{c}13.0 \\
10.0 \\
15.0 \\
20.0 \\
5.0 \\
10.0 \\
17.0 \\
17.0 \\
3.0\end{array}$ \\
\hline
\end{tabular}

Table 2 General geographic data among Asian immigrant employees after ASEAN community's policy $(\mathrm{N}=400)$ 


\begin{tabular}{|c|c|c|c|c|c|c|}
\hline Data & Percentage & $\begin{array}{l}\text { Mean } \pm \text { standard } \\
\text { deviation }\end{array}$ & Minimum & Maximum & Skewness & Kurtosis \\
\hline $\begin{array}{l}\text { Public health } \\
\text { administration }\end{array}$ & (less) $50 \%$ & $5.68 \pm 2.33$ & $\begin{array}{c}1 \\
\text { (none) }\end{array}$ & $\begin{array}{c}4 \\
\text { (most) }\end{array}$ & 0.76 & 0.74 \\
\hline $\begin{array}{l}\text { Need for mental } \\
\text { health care }\end{array}$ & (more) $34 \%$ & $\begin{array}{c}2.52 \pm 0.98 \\
\text { (more) }\end{array}$ & $\begin{array}{c}1 \\
\text { (none) }\end{array}$ & $\begin{array}{c}4 \\
\text { (most) }\end{array}$ & -0.06 & -1.01 \\
\hline $\begin{array}{l}\text { ASEAN community's } \\
\text { policy }\end{array}$ & (less) $45 \%$ & $2.00 \pm 0.90$ ( less) & $\begin{array}{c}1 \\
\text { (none) }\end{array}$ & $\begin{array}{c}4 \\
\text { (most) }\end{array}$ & -0.62 & -0.30 \\
\hline $\begin{array}{l}\text { Mental health } \\
\text { status }\end{array}$ & $\begin{array}{l}\text { (normal) } 74.7 \% \\
\text { (almost } \\
\text { abnormal) } 25.3 \%\end{array}$ & $\begin{array}{l}0.37 \pm 0.16 \\
\text { (normal) }\end{array}$ & $\begin{array}{c}0 \\
\text { (none/ } \\
\text { normal) }\end{array}$ & $\begin{array}{c}1 \\
\text { (abnormal) }\end{array}$ & -0.75 & -0.90 \\
\hline
\end{tabular}

Table 3 Overall test of model fit for causal model

\begin{tabular}{|l|c|}
\hline \multicolumn{1}{|c|}{ Criteria } & Value \\
\hline Chi-Square & 0.556 \\
Degrees of freedom & 1 \\
P-value & 0.45 \\
CFI (Comparative Fit Index) & 1.000 \\
TLI (Tucker-Lewis Index) & 1.002 \\
RMSEA (Root Mean Square Error of Approximation) & 0 \\
SRMR (Standardized Root-Mean-Square Residual) & 0.002 \\
R-square (ASEAN community's policy) & $0.679^{* *}$ \\
R-square (Mental health service utilization) & $0.666^{* *}$ \\
\hline
\end{tabular}

** $\mathrm{p}$ - value $<0.01$

Table 4 Direct, indirect, and total effect of causal model

\begin{tabular}{|c|c|c|c|c|c|c|}
\hline \multirow[t]{2}{*}{ Variable } & Mental & health & service & ASEAN & community's & policy \\
\hline & $\mathrm{DE}$ & IE & $\mathrm{TE}$ & $\mathrm{DE}$ & IE & $\mathrm{TE}$ \\
\hline Public health administration & $0.758^{* *}$ & - & $0.758^{* *}$ & - & - & - \\
\hline Need for mental health service & $0.545^{* *}$ & $0.048^{* *}$ & - & $0.427^{* *}$ & - & $0.427^{* *}$ \\
\hline Mental health status & $0.676^{* *}$ & $0.049^{* *}$ & - & $0.433^{* *}$ & - & $0.433^{* *}$ \\
\hline ASEAN community's policy & $0.113^{* *}$ & - & $0.113^{* *}$ & - & - & - \\
\hline
\end{tabular}

** $\mathrm{p}$ - value $<0.01$

$\mathrm{DE}=$ Direct Effect, $\mathrm{IE}=$ Indirect Effect, $\mathrm{TE}=$ Total Effect 